\title{
INTERRELACIÓN ICONOGRÁFICA DE THETYS Y THALASSA EN LOS MOSAICOS HISPANORROMANOS
}

\author{
Une corrélation iconographique de Thétys et de Thalassa dans \\ les mosaïques hispanoromaines
}

\author{
M. Pilar San Nicolás Pédraz*
}

Recibido el 10 de diciembre de 2007. Aceptado el 30 de enero de 2008.

\begin{abstract}
Resumen. Se recogen dos mosaicos de Jaén que han sido identificados tradicionalmente con la imagen de la diosa Thetys saliendo del mar. Tras el análisis de las series de imágenes musivas de la propia diosa Thetys y de la personificación del mar, Thalassa, se determina que en los pavimentos hispanos existe una interrelación iconográfica de ambos personajes y por lo tanto el eslabon de las simbiosis.

Palabras clave: Thetys. Thalassa. Mosaicos. Iconografía.
\end{abstract}

\begin{abstract}
Nous reprenons deux mosaïques de Jaén qui ont été traditionnellment identifiées comme l'image de la déesse Thétys sortant de la mer. Après analyse des nombreuses séries d'images de la déesse Thétys et de la personnification de la mer, Thalassa, on détermine que dans les pavements espagnols, is existe une corrélation iconographique entre les deux personnages et par conséquent un lien entre eux.
\end{abstract}

Key Words: Thétys. Thalassa. Mosaïques. Iconographie.

Tethys es la diosa del mar y simboliza la humedad que hace germinar todo. Hija de Urano y Gea, hermana y paredro de Océano (Hes. Theog. 136; Apoll. Bibl. I, 2, 1, 3), y madre de todos los ríos y de las tres mil Océanidas (Hes. Theog. 337370; Apoll. Bibl. I, 8, 2, 2; Diod. 4, 69; 72, 1). Thalassa es la personificación del mar'.

En la musivaria hispanorromana existen dos mosaico que se han identificado con la diosa Tethys saliendo del mar como la describe Homero (IL. $1.357 \mathrm{ss}$ ) con una peculiar iconografía, que queremos resaltar en homenaje al Prof. E. Ripoll Perelló. Ambos pavimentos se conservan en el Museo Arqueológico de Jaén. No obstante, la diosa Tethys podría estar representada en el mosaico Cosmológico de la Casa del Mitreo, en Augusta Emerita, de profundo simbolismo filosófico y fechado en la segunda mitad del siglo $\mathrm{II}^{2}$. En este gran pavimento Tethys estaría situada en el lado derecho, en una zona muy estropeada, y en contraposición a la figura de Océano, y probablemente figuraría de cuerpo entero y sentada como su paredro ${ }^{3}$. Esta iconografía de la diosa no es desconocida en los mosaicos romanos, la encontramos tanto sola (mosaicos de Antakya, del siglo III o principios del IV, y Tartous del siglo III) como con Océano (mosaicos de la Casa del Calendario, fechado en los comienzos del siglo II, y de la Casa de Océano y Tethys, del siglo III, en Antioquia, así como en Zeugma) ${ }^{4}$.

(*) Dpto. de Prehistoria y Arqueología. UNED. P. Senda del Rey, 7. 28040-Madrid. psan@geo.uned.es.

(1) LESKY, A.: Thalatta der weg der griechen zummeer, Nueva York 1973, págs. 8-13.

(2) BLANCO A.: Mosaicos romanos de Mérida, CMRE II, Madrid 1978, pág. 38, fig. 1, láms. 36-37; QUET, M. H.: La mosaïque cosmologique de Mérida, 1981; BLÁZQUEZ, J. M.: "Cosmología mitraica en un mosaico de Augusta Emérita”, AEspA 59, 1986, págs. 89- 100; FERNÁNDEZ GALIANO, D.: "Observaciones sobre el mosaico de Mérida con la Eternidad y el Cosmos», Anas 2/3, 1989- 1990, págs. $173-182$.

(3) TORRES CARRO, M.: "Iconografía marina. Mosaicos romanos. Estudios sobre Iconografía». Actas de Homenaje in Memoriam de A. Balil, Madrid 1990, pág. 131, nota 132.

(4) Véase estos ejemplares en LÓPEZ MONTEAGUDO, G.: Oceanus on the Roman Mosaic Pavements of Spain". Proceedings of the Symposium 12 International Conferense 'Cura Aquarum in Ephesus', Leiden 2006, págs 497- 503; LÓPEZ MONTEAGUDO, G.: "La iconografía del dios Océanos en los mosaicos hispano-romanos", Xo Coloquio Internacional/Aiema. 0 Mosaico Antigonos centros e nos periferias: originalidades, influencias e identidades (Conímbriga, Portugal 2005), en prensa. BLAZZUEZ, J.M. et alii: "Representaciones mitológicas, leyendas de héroes y retratos de escritores en los mosaicos de época imperial en Siria, Fenicia, Palestina, Arabia, Chipre, Grecia y Asía Menor", Antigüedad y Cristianismo (Murcia), 2004, pág. 296, fig. 12. 


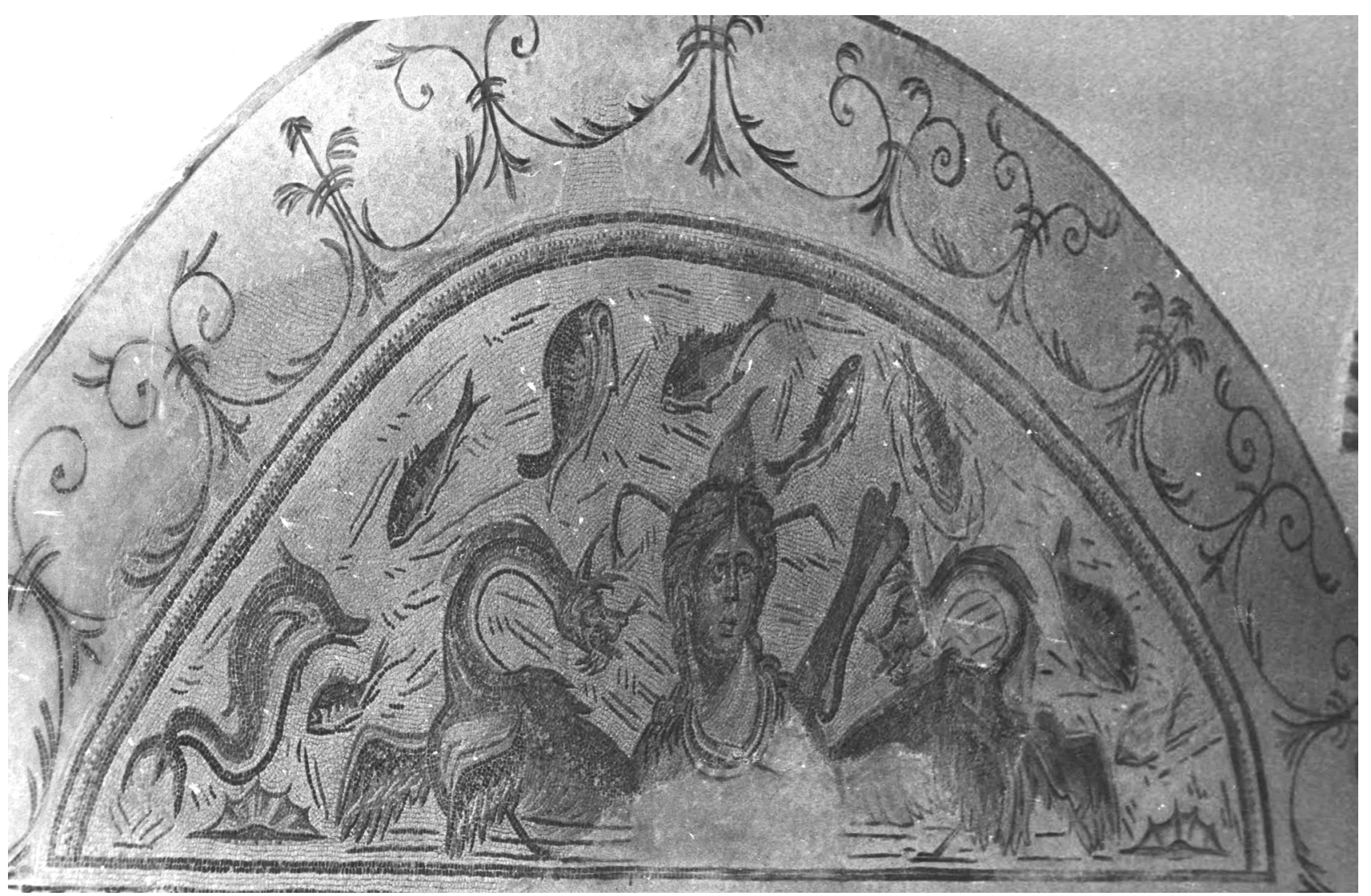

A Figura 1. Mosaico de Marroquies Altos, Jaén capital.

Uno de los ejemplares hispanos en estudio fue hallado en 1959 en Jaén capital, en la zona de Marroquies Altos. En el mismo lugar y a un nivel más inferior aparecieron otros pavimentos muy deteriorados con decoración geométrica, así como otros a unos $15 \mathrm{~m}$ que fueron destruidos ${ }^{5}$. El mosaico tiene forma semicircular, posiblemente pertenezca a una exedra de una habitación de prestigio, como el oecus, o a una fuente, y está fechado en la segunda mitad del siglo IV ${ }^{6}$. Se representa el busto de Tethys que lleva un ala o aleta en la parte posterior de la cabeza y patas de cangrejo a ambos lados de ésta; en el cuello, a modo de collar, se enrosca un pez serpentiforme. La figura está situada entre dos khetoi que la miran. A su izquierda figura un remo. Delfines, peces y una concha rodean a la diosa (fig. 1).

El otro ejemplar fue localizado en el panel oeste de la estancia 32 de la villa de Bruñel (Quesada, Jaén), descubierta en
1924, y está fechado en la segunda mitad del siglo III o principios del IV7 (fig. 2). El pavimento es de forma rectangular, con un marco tipo "Oxford" de origen oriental, enmarcado a su vez por una franja de ovas truncadas y de puntas tangentes, motivo que aparece en Antioquía (Turquía) y Tesalónica $(\text { Grecia) })^{8}$ y conocido en la Península lbérica en los mosaicos de Barcelona y Tarragona ${ }^{9}$. En el cuadrado central aparece un busto femenino muy restaurado, particularmente en la cabeza y arranque del pecho, que por similitud con el de Marroquíes Altos se ha identificado como Tethys ${ }^{10}$. Lleva el pelo desordenado o mojado, indicando que sale del agua, patas de cangrejo y algunas algas en la cabeza, así como una serpiente enrollada al cuello en forma de collar (fig. 3). La asociación marco tipo "Oxford" a la figura de Tethys se encuentran en dos pavimentos de Antioquía, el de la Casa de Océano y Tethys y la Casa del Mar de los Dioses ${ }^{11}$

(5) ESPANTALEÓN, R., "La necrópolis en una cueva artificial de Marroquies Altos", BIEG 6, 1960, pág. 42.; CAN 12, 1973, láms. X-XI.

(6) BLÁZQUEZ, J. M. Mosaicos romanos de Córdoba, Jaén y Málaga, CMRE III, Madrid 1981, págs. 59- 60, n 37, láms. 44-45.

(7) MUÑOZ JOFRÉ, L. "Sobre los mosaicos de Bruñel y su actual estado de conservación", en De las sociedades agrícolas a la Hispania romana, Jornadas Históricas del Alto Guadalquivir, Quesada (1992-1995), Jaén 1999, pág. 257; POLAINO, L., Don Juan de Mata. Homenaje al profesor Carriazo II. Sevilla 1972, p. 35; BLÁZQUEZ, J.M.: op. cit. nota 6, pág. 64, nº. 43, lám. 52.

(8) BALMELLE, C. et alii: Le décord géometrique de la Mosaïque romaine I. Répertoire graphique et descriptif des composition linéaires et isotropes, Paris 2002, T. I, pág. 101, lám. 51e.

(9) BALIL, A.: "El mosaico de las Tres Gracias de Barcelona ", AEspA 97. 1958, págs. 89- 92, con un gran repertorio de pavimentos; GUARDIA PONS, M.: Los mosaicos de la Antigüedad Tardía en Hispania. Estudios de iconografía, Barcelona 1992, pág. 171.

$\left({ }^{10}\right)$ FERNÁNDEZ GALIANO, D.: «Nuevas interpretaciones iconográficas a mosaicos hispanos», Museos I, 1982, pág. 17. El autor confunde la procedencia de este mosaico y lo ubica en la villa de Martos.

(11) LEVI, D.: Antioch Mosaic Paviments, Princeton 1947, láms; BALIL, A.: op. cit. en nota 9, pág. 90; MUÑOZ JOFRÉ, L.: op. cit. en nota 7, pág. 257. 


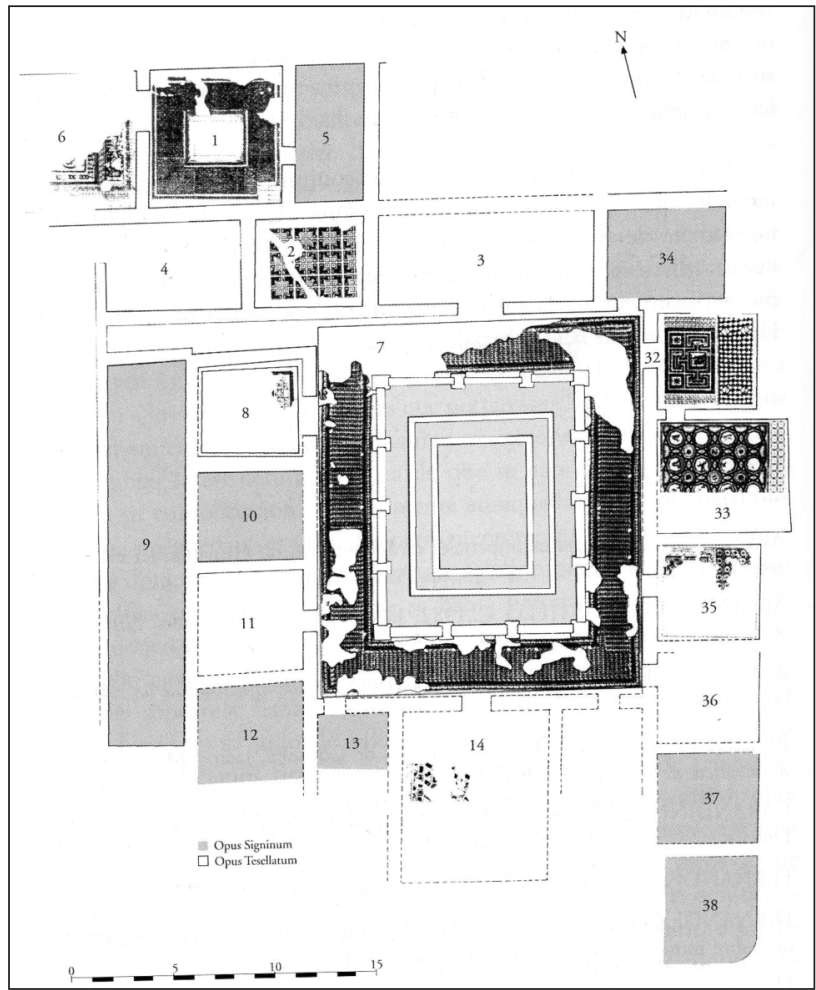

$\Delta$ Figura 2. Plano en planta de los mosaicos de la villa de Bruñel, Jaén (según Muñoz Jofré).

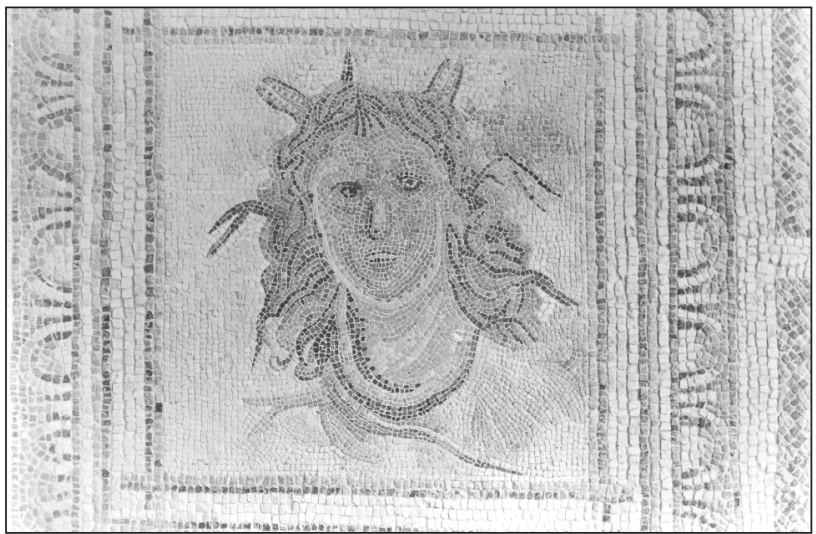

A Figura 3. Mosaico de la villa de Bruñel, Quesada, Jaén.
La iconografía de Tethys sola y en busto aparece en varios mosaicos de los siglos III y IV, hallados principalmente en la parte oriental del Imperio, en Antioquía y Shahba Philippopolis (Siria), además de los ejemplares de Italia y Gran Bretaña ${ }^{12}$. El contexto marino de peces es la constante en todos ellos, mientras que el khetos aparece generalmente enrollado alrededor de su brazo como en los ejemplares de Anazarbes $\left(\right.$ Sicilia) ${ }^{13}$ y de Shahba Philippopolis que se conserva en el museo de Souweida ${ }^{14}$, o enrollado en el cuello en otro mosaico de Shahba Philippopolis conservado in situ ${ }^{15}$, y en el pavimento de Antioquia de la Casa del barco de Psiques, hab. $6^{16}$. El atributo del remo aparece, además de en los mosaicos anteriores, en el pavimento de las Termas F de Antioquia ${ }^{17}$, que se conserva en la colección americana de Dumbarton Oaks ${ }^{18}$. Este ejemplar es el único que va acompañado con una inscripción con su nombre en griego que la identifica, según Sara M. Wages, con Tethys y no con la nereida Thétis como proponía D. Levi (fig. 4). La misma investigadora modifica la datación propuesta por D. Levi y señala el periodo 325-360 por razones iconográficas y por la arquitectura del edificio.

El atributo de las aletas a los dos lados de la cabeza es una constante en todos los ejemplares de Tethys, ya sea sola o con Océano, de cuerpo entero o en busto ${ }^{19}$, como el de Zeugma (fig. 5). Sin embargo en el ejemplar hispano de Marroquíes Altos solo lleva un ala o aleta detrás de la cabeza, mientras que las patas de cangrejo que porta los pa-



A Figura 4. Mosaico de las Termas F de Antioquía. Colección Dumbarton Oaks.

(12) LIMC VIII, "Thetys I", no. 7-14.

(13) BUDDE, L.: Antike Mosaiken in Kilikien I. Die heidnischen Mosaiken, 1969, págs. 92-95, fig. 179; FABBRICOTTI; E.: "Una Tethys venosita", Atti e memoire della Società Magna Grecia 15-16, pág. 215, n 11, lám. 99.

(14) BALTY, J.: "La mosaïque antique au Proche-Orient I. Des origines à la Tétrarchie", ANRW XII 2, 1981, págs. 410-411; DENTZER, J. -M. et alii, Le Djebel al- 'Arab, Histoire et patrimoine au Musée de Suweida, 1991, pág. 143, n 8,58, lám. G.

(15) BALTY, J.: Mosaïque antiques de Syrie, Bruselas 1977, págs. 66-67, n 28-29; Eadem, "Mosaici antichi di Siria e di Giordania", en I mosaici di Giordania, Roma 1986, pág. 108, fig. 89.

${ }^{(16)}$ LEVI, D.: op. cit. en nota 11, pág. 186, láms 39b, 157b; BUDDE, L.: Antike Mosaiken in Kilikien II. Die heidnischen Mosaiken, 1972, pág. 85, figs. 213-214; FABBRICOTII, E.: op. cit. en nota 13, pág. 214, n 4, lám. 98b.

(17) LEVI, D.: op. cit. en nota 11, págs. 258-259, láms 62, 163a.

(18) WAGES, S. M.: "A note on the Dumbarton Oaks Tethys Mosaics", Dumbarton Oaks Papers 40, 1986, págs. 119- 128. No hemos podido consultar la Tesis Doctoral de M. Sicard, Téthys et Thalassa à l'époque hellénistique et romaine, Ungedruckte Magisterarbeit Québec, Univ. Laval, 1989.

(19) LIMC VIII, "Thetys I"; WAGNER, J.: Seleukia am Euphrat, Zeugma. Studien zur historischen Topographie und Geschichte, Wiesbaden 1976 : KENNEDY, D. L.: "Zeugma. Une ville antique sur I'Euphrate", Archéologia 306, 1994, pp. 26- 35; ÖNAL, M.: Mosaics of Zeugma, Estambul 2002, págs. 35-37. 




\ Figura 5. Mosaico de Zeugma (Turquía).

FigurA 6. Mosaico de Garni (Armenia).

vimentos hispanos no aparecen en ningún ejemplar de la serie, y son más propias de Océano y de Thalassa. Esta última, personificación femenina del mar, también aparece en la musivaria oriental y en la del Norte de África con la misma iconografía que Thetys, en busto, sola o con Océano, con remo, monstruos marinos, delfines y otros peces; no lleva alas o aletas en la cabeza y en su lugar porta casi siempre las patas de cangrejo ${ }^{20}$. Así aparece en los pavimentos de Madaba (Jordania) ${ }^{21}$, Garni (Armenia) ${ }^{22}$, aquí junto con Océano (fig. 6), Tagiura (Libia) y el posible de Siria (fig. 7), fechados entre los siglos II al VI. Todos estos ejemplares suelen llevar su nombre en griego para su identificación iconográfica excepto en los dos ejemplares de la habitación 45 y del tablinum 6 de la villa de la "Gara de las Nereidas" de Tagiura, del siglo II, por lo que fueron identi-

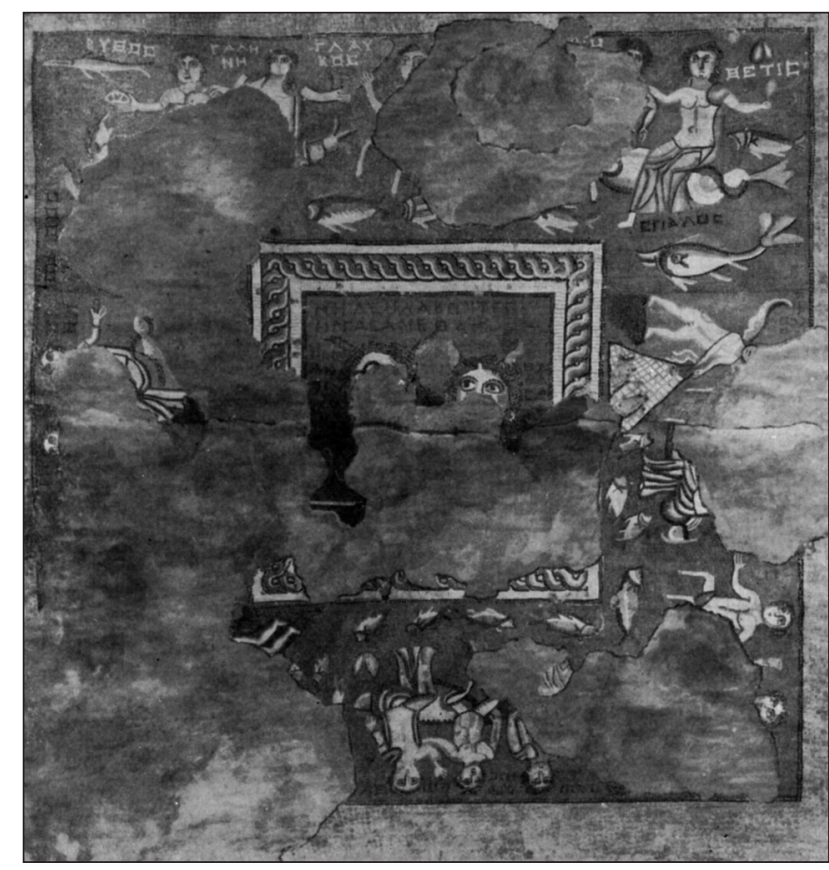

(20) LIMC VIII, "Oceanus", no 53; LIMC VIII, "Thalassa", no 11-14

(21) PICCIRILLO, M.: The Mosaics of Jordan, Jordania 1993, págs. 96 y 98, láms. 78 y 80 . Este ejemplar, de finales del siglo VI no lleva las patas de cangrejo en la cabeza pero porta el timón y la serpiente enrrollada en el hombro, además está identificada con su nombre.

(22) TREVER, K. V.: "Garni", Enciclopedia dell'Arte Antica III, 1960, pág. 794, fig. 985; VOSTCHININA, A.: "Mosaïques gréco-romaines trouvées en Union Soviétique", La Mosaïque gréco-romaine I, Paris 1965, págs. 319-321, figs. 6-8. 


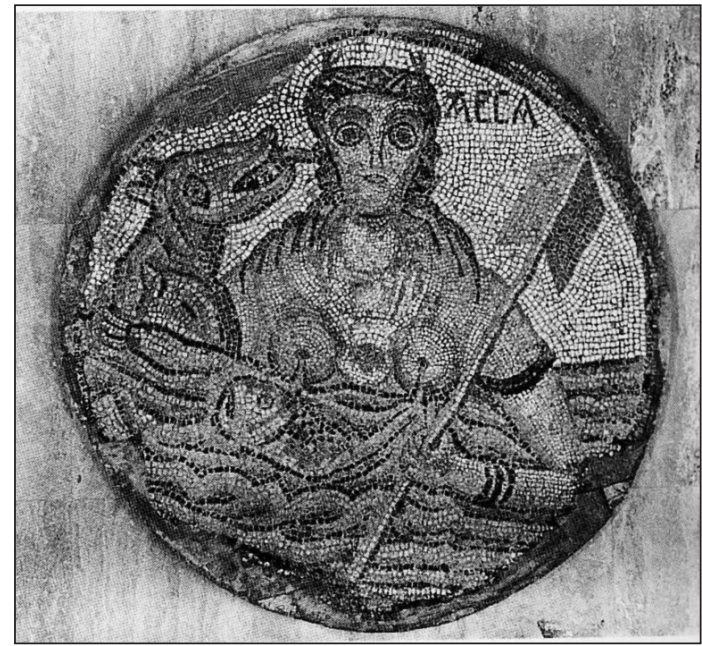

A Figura 7. Mosaico de Siria.

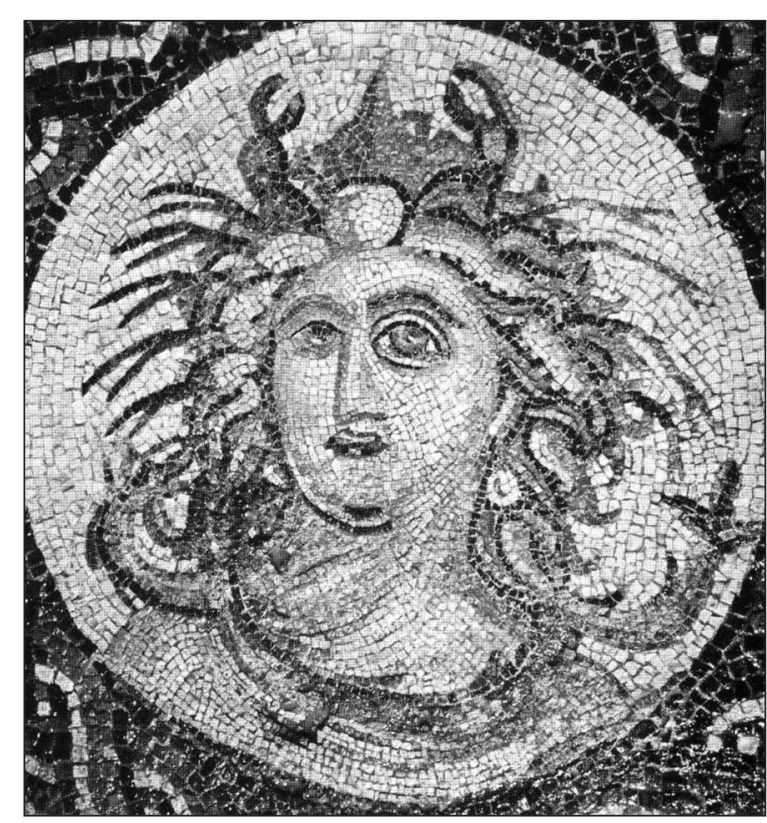

- Figura 9. Mosaico de la villa de la Gara de las Nereidas, Tagiura, Libia. Tablinum 6.

ficadas como Anfitrite ${ }^{23}$ (figs. 8 y 9). Estos dos ejemplares serían los paralelos más próximos para la figura del mosaico hispano de Bruñel puesto que llevan el khetos enrollado en el cuello, así como el pelo desordenado o mojado, patas de cangrejo y algunas algas en la cabeza. Igualmente se añadiría el mosaico de Yakto de Antioquía cuya figura fue atribuida a Thetys ${ }^{24}$ y actualmente identificada con Thalas$\mathrm{sa}^{25}$, señalando Sara M. Wages que esta imagen sería la última fase de la serie de la evolución iconográfica de Thetys/ Thalassa. Esta figura emerge del mar entre erotes sobre del-

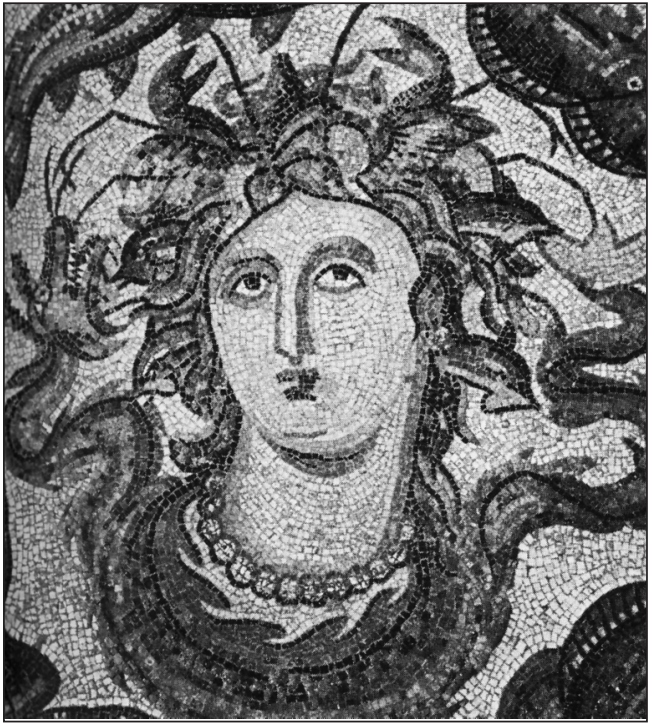

- Figura 8. Mosaico de la villa de la Gara de las Nereidas, Tagiura, Libia. Habitación 45.

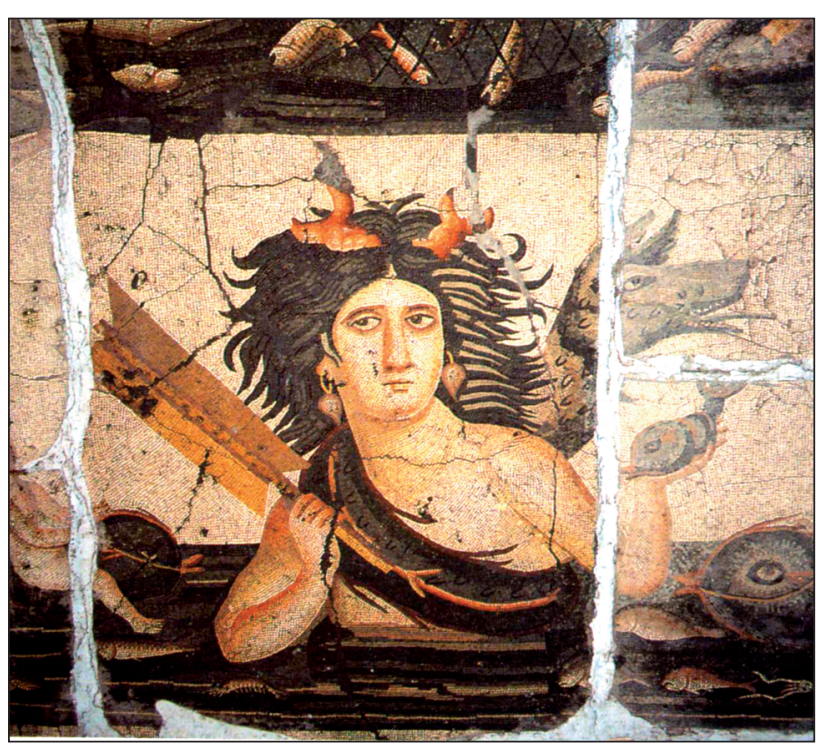

A Figura 10. Mosaico de Yakto de Antioquia.

fines y escenas de pesca. Lleva el khetos enrollado sobre su pecho, el pelo desordenado, portando en su mano derecha el remo y en la izquierda un pez (fig. 10).

En el ejemplar de Marroquies Altos aparece solo un ala o aleta, atributo propio de Thetys, junto a las patas de cangrejo atributo de Thalassa, aqui existe una interrelación iconográfica entre ambos personajes aunque con notable particularidad, por lo que creemos que en Hispania se encuentra el eslabón de la simbiosis o contaminación de ambas iconografías, al conjuntarse ambos atributos.

(23) VITA, A. DI.: La villa della "Gara delle Nereidi presso Tagiura: un contributo alla storia dell mosaico romano, ed. Altri resenti scavi e scoperte in Tripolitania, Tripoli 1966, pág. 34, lám. 8a; DUNBABIN, K.M.D.: The mosaics of roman North Africa. Studies in Iconography and Patronage, Oxford 1978, pág. 272; LIMC I, "Amphitrite", no. 7- 8.

(24) LEVI, D.: op. cit. en nota 11, págs. 323-326, láms 75, 76a.

(25) WAGES, S. M.: op. cit. en nota 18, pág. 125, fig. 6. 